\title{
Human factors validation for a rheumatoid arthritis auto-injector for the adalimumab biosimilar FKB327
}

\section{Talia Serrecchia* and Kimberly A. Waller}

Human Research \& Regulatory Affairs Lead, Ximedica, 55 Dupont Drive, Providence, RI 02907, USA

Email: TSerrecchia@ximedica.com

Email: KWaller@ximedica.com

*Corresponding author

\section{Tomoyoshi Ishikawa}

Analytical and Formulation Development Department, Fujifilm Kyowa Kirin Biologics Co., Ltd., Ohtemachi Building, 1-6-1, Ohtemachi, Chiyoda-ku, Tokyo 100-0004, Japan

Email: Tomoyoshi.ishikawa@fk-b.com

\section{Rafael Muniz}

Global Medical Affairs, Mylan, 1000 Mylan Blvd., Canonsburg, PA 15317, USA Email: Rafael.muniz@mylan.com

\section{Thomas R. Varricchione}

Clinical Research \& Regulatory Affairs, Ximedica, 55 Dupont Drive, Providence, RI 02907, USA Email: TVarricchione@ximedica.com

\begin{abstract}
Rheumatoid arthritis (RA) is a chronic autoimmune disorder, often treated with adalimumab. This study was designed to validate usability of the adalimumab biosimilar FKB327 auto-injector (AI) and document risk associated with the device. A total of 136 participants were enrolled, including patients with RA, caregivers of patients with RA, and healthcare providers of patients with RA. Use errors and close calls were evaluated during 2 simulated injections. A full dose was administered by $90.4 \%$ and $97.8 \%$ of users for the first and second injections, respectively. The most common use errors were failure to squeeze injection site, check expiration date, check medication in viewing window, and rotate injection site during the second injection. The device, packaging, and instructions received favourable user ratings. FKB327$\mathrm{AI}$ is an easy-to-use device for patients with RA, their caregivers, and healthcare providers. Errors that could lead to incorrect dose were infrequent and not associated with serious harm.
\end{abstract}


Keywords: adalimumab biosimilar; autoinjector; human factors validation; device usability validation; rheumatoid arthritis; rheumatoid arthritis caregivers; rheumatoid arthritis patients; safety analysis; simulated injections; user error analysis.

Reference to this paper should be made as follows: Serrecchia, T., Waller, K.A., Ishikawa, T., Muniz, R. and Varricchione, T.R. (2020) 'Human factors validation for a rheumatoid arthritis auto-injector for the adalimumab biosimilar FKB327', Int. J. Human Factors and Ergonomics, Vol. 7, No. 2, pp.144-160.

Biographical notes: Talia Serrecchia is currently Human Research \& Regulatory Affairs Lead at Ximedica in Providence, RI. She earned a Bachelor of Science degree in Neuroscience from Brown University, Providence, RI, in 2005. Her combined experience in pharmaceutical clinical research, human factors usability in medical device development, risk management, and US regulatory strategy allows her to provide support in bringing safe, effective, and intuitive medical devices to market. By applying the knowledge and skills obtained from years of conducting regulated clinical trials to the realm of human factors usability, she provides a unique perspective to medical device development. She has learned that medical device development is an iterative process, and that human factors goes hand-in-hand with risk management during product design.

Kimberly A. Waller, $\mathrm{PhD}$, currently serves as a Clinical \& Regulatory Program Manager at Ximedica, Providence RI. She earned her $\mathrm{PhD}$ in Biomedical Engineering from Brown University, Providence, RI, in 2013 after completing her undergraduate work at Boston University, MA. She has authored multiple publications in scientific journals, along with presenting abstracts at the Annual Meeting of the Orthopaedic Research Society. Her previous positions included posts as a postdoctoral research associate, and then a research scientist, at Rhode Island Hospital, Providence, RI; as an instructor in orthopedics (research) at the Warren Alpert Medical School of Brown University; and as Human Research \& Regulatory Affairs Lead at Ximedica.

Tomoyoshi Ishikawa, $\mathrm{PhD}$, is a former Senior Scientist of combination product development and currently serves as Manager of the Production Planning Department at Fujifilm Kyowa Kirin Biologics Co., Ltd, in Tokyo, Japan. His tenure as a scientist at Fujifilm Kyowa Kirin has spanned nearly two decades. $\mathrm{He}$ earned a $\mathrm{PhD}$ in Engineering from Gunma University in Gunma, Japan, in 2010. Prior to that, he obtained his Master of Science in pharmaceutical sciences in 2000 from Osaka University in Osaka, Japan. He has been both author and co-author of several publications on biopharmaceutics research in peer-reviewed, scientific journals.

Rafael Muniz, MD, is currently the Head of Global Medical Affairs at Mylan Inc., in Canonsburg, PA, where he leads a team of more than 150 medical affairs professionals across all geographies and several therapeutic areas. $\mathrm{He}$ earned a medical degree from UTESA: Universidad Tecnologica de Santiago in Santiago de los Caballeros, Dominican Republic, in 1984. He trained in family practice at the Medical College of Wisconsin, Milwaukee, WI, and in psychiatry at Bergen Regional Medical Center in New Jersey. He is author and co-author of more than 120 publications and abstracts, and he has extensive experience in clinical development and medical affairs in the pharmaceutical industry. In addition, he has experience in several New Drug Applications (NDAs) and supplemental NDA submissions to the US Food and Drug Administration, along with several successful product launches and life-cycle management of several products. 
Thomas R. Varricchione is the Senior Vice President of Clinical \& Regulatory Affairs, Ximedica, LLC, Providence, RI. He has held senior positions with several medical device companies, developing products and obtaining more than 50 first-time marketing and clinical research authorisations, and led several clinical trials and postmarket registries of novel products. He holds a Master of Business Administration from Boston University, a Certificate in Respiratory Care from Northeastern University, and a Bachelor of Arts with honours from the University of Vermont, Burlington. He has spoken at medical device industry conferences, has co-authored several peer-reviewed papers, and is a Registered Respiratory Therapist.

\section{Introduction}

Rheumatoid arthritis (RA) is the most common autoimmune inflammatory arthritis among adults. RA causes inflammation of synovial lining and damage to joints and cartilage, which can result in severe and painful deformity and disability. Although RA primarily involves the joints, serious extra-articular manifestations include pulmonary involvement, vasculitis, and other systemic comorbidities (Smolen et al., 2016; Ostrowska et al., 2018). RA is increasing in prevalence, affecting approximately 1.36 million people in the USA (Singh et al., 2016; Helmick et al., 2008; Hunter et al., 2017).

In RA treatment guidelines, the American College of Rheumatology recommends initiating treatment with disease-modifying antirheumatic drugs (DMARDs) in newly diagnosed RA. For RA that is not responsive to DMARD therapy, injectable biologics usually tumour necrosis factor (TNF) inhibitors - are the recommended therapeutic options. Several TNF inhibitors are now commercially available, including adalimumab, certolizumab pegol, etanercept, golimumab, and infliximab (Singh et al., 2016). Biosimilars for the many anti-RA biologics are now coming to market, offering more options and cost-savings for consumers (Grewal et al., 2018).

Effective treatment with biologics requires long-term adherence to medication (Murage et al., 2018). Low adherence and non-adherence are associated with worse outcomes, underscoring the importance of interventions to improve adherence to biologic therapy (Bluett et al., 2015). One option for improving adherence is through selfadministration, which eliminates the need for additional hospital visits and increases independence. Self-administration of biologics is correlated with higher patient adherence than provider administration, potentially leading to improved adherence and reduced costs (Schwarzenbach et al., 2014; Xiao et al., 2018; Dashiell et al., 2018; Schulze-Koops et al., 2015).

Treatments for RA can be self-administered using a variety of mechanisms, including prefilled syringes, syringes with vials, and auto-injectors (AIs). Compared with prefilled syringes, AIs are often preferred by patients because of the ease of use, convenience, time-savings, and safety of these devices (Paul et al., 2012; Kivitz et al., 2006). People who have an aversion to needles also prefer to use AIs over prefilled syringes (Stockl et al., 2007). Moreover, the hands and wrists are frequently impacted by RA, leading to hand deformities, reduced grip strength, lower coordination, and decreased dexterity (Figure 1; Erol et al., 2016). Therefore, easy-to-grip AIs may be preferred to syringes, 
which require more coordination. Examples of AI features that have been designed with grip in mind include a surface that is not too slick or slippery and a diameter that is comfortable to hold in an adult hand. Thus, the usability of AIs is an important efficacy and safety consideration to avoid errors that could cause harm to end users.

Figure 1 Use of FKB327-auto-injector by a person with manual dexterity issues (see online version for colours)

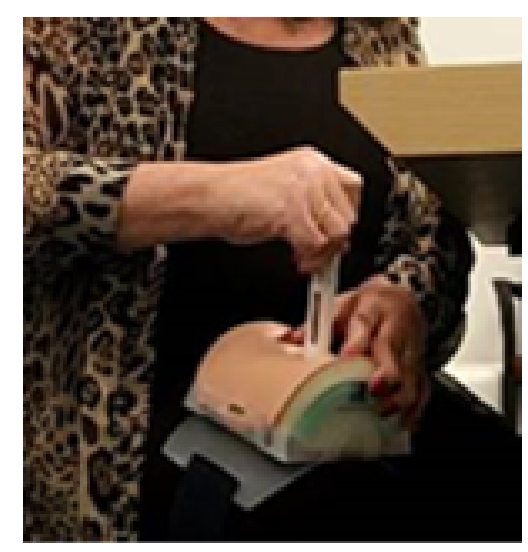

Formal processes have been developed to characterise the types of errors and evaluate the frequencies of those errors during real-world usage, with the ultimate goal of creating products that are easy to use and safe (Medicines \& Healthcare products Regulatory Agency, 2017). Use error analysis (UEA) is the process in which a user's tasks are broken down, and potential use errors during each task are identified during product design (Bligård and Osvalder, 2014; Hooper and Hitchens, 2011). Hooper and Hitchens proposed a method for identifying potential use errors in a user-centred fashion by integrating the user into the device system, performing detailed task and hazard analysis, and revising failure modes and effects analysis (FMEA) documents to incorporate those findings (Hooper and Hitchens, 2011). Their process estimated both severity and frequency of hazards, but regulatory requirements for usability validation place the most emphasis on the severity of potential harm. Our process reflected this and placed emphasis on critical tasks, which could lead to a high severity of harm if not performed or performed incorrectly. Once a list of predicted errors has been generated in the UEA, human factors engineering principles are then applied in a number of ways, including a usability test, in which end-users have the opportunity to interact with a device model in a simulated setting to detect use errors (Hegde and Respironics, 2013).

FKB327 is an adalimumab biosimilar that was developed to be administered using a biologic-device combination product (FKB327-AI) designed to deliver a single 40-mg subcutaneous dose of adalimumab. FKB327-AI is intended for self-administration by patients with RA, administration by caregivers of patients with RA, and administration by healthcare providers who treat patients with RA. The objective of this usability study was to evaluate the ability of representative end users to safely and correctly use the to-be-marketed FKB327-AI device and to assess the clarity and comprehensibility of the device instructional materials through simulated use and product knowledge questions. 


\section{Materials and methods}

\subsection{Study design}

This study was an in vitro, non-clinical human factors validation study of the usability of FKB327-AI (Figure 2). Product usability was evaluated by simulating a typical productuse scenario for 3 end-user categories: patients with RA, caregivers of patients with RA, and healthcare providers who care for patients with RA, including nurses, nurse practitioners, and physicians. The study was designed and performed in accordance with the US Food and Drug Administration (FDA) Guidance for Industry, "Applying Human Factors and Usability Engineering to Medical Devices" (2016) and consideration of additional factors described in FDA's Draft Guidance Document entitled "Human Factors Studies and Related Clinical Study Considerations in Combination Product Design and Development" (2016). This study was performed between March 23, 2016, and June 2, 2016. This research complied with the tenets of the Declaration of Helsinki and was approved by the New England Institutional Review Board (IRB \#16-052). Informed consent was obtained from each participant.

Figure 2 Autoinjector schematic (see online version for colours)

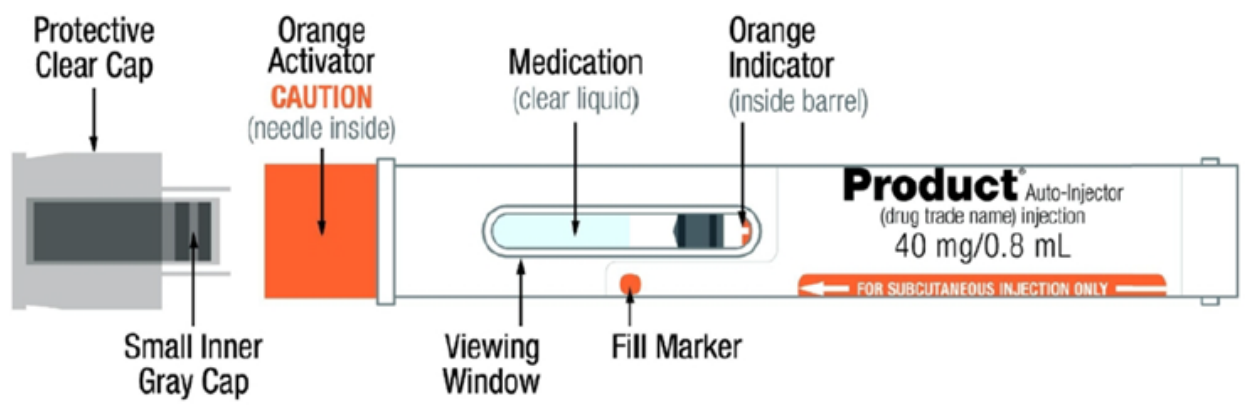

\subsection{Participants}

Participants were representative end users aged 20 to 77 years who were recruited from the greater Providence, RI; Boston, MA; and Minneapolis/St. Paul, MN, areas. A total of 136 participants were enrolled: 60 patients, 61 caregivers, and 15 healthcare providers. Approximately half of enrolled patients and caregivers were injection-naïve. Patients and caregivers were categorised as injection-naïve if they had never given themselves or another person an injection using a needle and syringe, pen, jet, or related AI. Inclusion and exclusion criteria are described in Table 1.

\subsection{Training}

Patient and caregiver participants either received verbal and hands-on training by nurse educators (trained) or were untrained. All users were given the to-be-marketed version of the product in its intended packaging, including instructional materials, during the usability session. Trained participants completed their first injection a minimum of 60 minutes after training to simulate administration of the first injection, after leaving the 
doctor's office, picking up medication from the pharmacy, and returning home. A planned distraction activity was introduced during the 60-minute window to interfere with training retention. All healthcare providers were untrained.

Table 1 Inclusion and exclusion criteria for all participants

\begin{tabular}{|c|c|}
\hline Inclusion criteria & Exclusion criteria \\
\hline \multicolumn{2}{|l|}{ All } \\
\hline & $\begin{array}{l}\text { - Being employed by, or living with someone } \\
\text { employed by, a pharmaceutical company } \\
\text { - The presence of serious health conditions that } \\
\text { prevented participation } \\
\text { - Inability to comply with the study schedule } \\
\text { - Participation in an injection study in the past } \\
\text { three months } \\
\text { - Participation in a previous FKB327 formative } \\
\text { usability or pilot study }\end{array}$ \\
\hline \multicolumn{2}{|l|}{ Patients } \\
\hline $\begin{array}{l}\text { - Formal diagnosis of RA } \\
\text { - Impairment of the hands, classified as } \\
\text { mild, moderate, or severe }\end{array}$ & $\begin{array}{l}\text { - Currently or previously employed as a healthcare } \\
\text { professional } \\
\text { - Low health literacy, defined as a REALM score } \\
<19 \text {, which corresponds to a reading level of } \\
\text { grade } 3 \text { or below (Institute of Medicine } \\
\text { Committee on Health Literacy, 2004) }\end{array}$ \\
\hline \multicolumn{2}{|l|}{ Caregivers } \\
\hline $\begin{array}{l}\text { - Cared for patients with RA by helping } \\
\text { with daily tasks at least one day per week }\end{array}$ & $\begin{array}{l}\text { - Currently or previously employed as a healthcare } \\
\text { professional } \\
\text { - Low health literacy, defined as a REALM score } \\
<19 \text {, which corresponds to a reading level } \\
\text { <grade } 3 \text { (Institute of Medicine Committee on } \\
\text { Health Literacy, 2004) }\end{array}$ \\
\hline \multicolumn{2}{|l|}{ Healthcare providers } \\
\hline \multicolumn{2}{|l|}{$\begin{array}{l}\text { - Currently licensed and practicing } \\
\text { healthcare }\end{array}$} \\
\hline
\end{tabular}

Note: RA indicates rheumatoid arthritis; REALM, Rapid Estimate of Adult Literacy in Medicine.

\subsection{Usability sessions}

The simulated-use scenarios for patients, caregivers, and healthcare providers evaluated tasks required for self-administration or administration of adalimumab. Patients and caregivers participated in two injection scenarios, simulating the adalimumab dosing schedule. Healthcare professionals performed the two injection scenarios in the same session but were asked to assume two weeks had passed between injection scenarios. All participants used fully functional AI devices filled with water for injection, which did not 
contain active ingredients. Patients simulated self-administration into an injection pad attached to an area of their bodies of their choice. Caregivers and healthcare providers simulated patient administration into an injection pad attached to an injection area of their choice on a mannequin.

Table 2 Tasks and critical tasks

\begin{tabular}{|c|c|c|}
\hline Task & Potential clinical impact & Critical task \\
\hline Proper device storage ${ }^{\mathrm{a}}$ & $\begin{array}{l}\text { Administration of ineffective, } \\
\text { degraded, or precipitated drug and } \\
\text { swallowing of movable part }\end{array}$ & Yes \\
\hline Remove AI from device packaging & No treatment & No \\
\hline Check expiration date & $\begin{array}{l}\text { Administration of ineffective, } \\
\text { degraded, or precipitated drug }\end{array}$ & Yes \\
\hline Check medication in viewing window & $\begin{array}{l}\text { Administration of ineffective, } \\
\text { degraded, or precipitated drug }\end{array}$ & Yes \\
\hline Select correct injection site & $\begin{array}{l}\text { Intradermal or intramuscular drug } \\
\text { administration }\end{array}$ & Yes \\
\hline Wash hands & Microbiological contamination & No \\
\hline Wipe injection site with an alcohol prep pad & Microbiological contamination & No \\
\hline Remove AI cap & No treatment & Yes \\
\hline Squeeze injection site to create a raised area & Intramuscular drug administration & Yes \\
\hline $\begin{array}{l}\text { Orient orange activator end toward injection } \\
\text { site }\end{array}$ & Mechanical tissue irritation & Yes \\
\hline Place AI at $90^{\circ}$ angle to the injection site & Intradermal drug administration & Yes \\
\hline $\begin{array}{l}\text { Push AI down against the injection site so } \\
\text { first click is heard }\end{array}$ & No treatment & Yes \\
\hline $\begin{array}{l}\text { Do not move, twist, or rotate AI during } \\
\text { injection }\end{array}$ & Mechanical tissue irritation & Yes \\
\hline Administer a full dose & $\begin{array}{l}\text { Less than nominal drug volume } \\
\text { administered }\end{array}$ & Yes \\
\hline Pull AI straight away from injection site & Mechanical tissue irritation & No \\
\hline Dispose of AI in a sharps container & $\begin{array}{l}\text { Third-party exposure to non-sterile } \\
\text { needle tip }\end{array}$ & Yes \\
\hline Rotate and change injection site each time $\mathrm{e}^{\mathrm{b}}$ & Mechanical tissue irritation & Yes \\
\hline
\end{tabular}

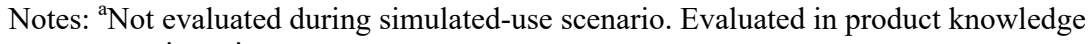
questionnaire.

${ }^{\mathrm{b}}$ Evaluated for second injection only.

$\mathrm{AI}$ indicates auto-injector.

During the sessions, study personnel included a moderator and a data recorder in the room with the participant. All other study or sponsor staff observed tasks in a separate room through a one-way mirror. Audiovisual recordings of the usability sessions were made for later review, if needed. 
All use errors and close calls were followed up with a postuse interview to determine how and why the participant believed the error occurred (root-cause inquiry). Participants were also asked to rate the ease of use of the product and the clarity of the instructional materials on a modified Likert scale.

Tasks required for safe and correct administration of drug with the AI were assessed in this study and are listed in Table 2. A participant's performance on each task was categorised as a success, success with close call, or use error. A use error occurred if a success was not reached. A close call was defined as a success that occurred after the participant

1 displayed confusion or hesitation in completing the task

2 omitted or improperly performed a step but corrected the use error and completed the task successfully

3 reported difficulty with the task and almost performed it incorrectly but corrected the error to complete the task successfully.

A subset of tasks was considered critical (Table 2), meaning the tasks could cause harm to the patient or user (including harm from compromised medical care) if performed incorrectly. Critical tasks were identified for the AI product using an advanced FMEA to assess the severity of risk to the user and patient, as well as any potential impact with respect to usability that may compromise patient care.

Participants also responded to product knowledge questions developed to evaluate aspects of use not conducive to simulated-use testing, including critical tasks such as proper device storage.

\subsection{Data analysis}

In addition to the aggregate data analysis, sensitivity analysis was performed to evaluate the occurrence of use errors among user groups; between injection-naïve and injection-experienced users; and between trained and untrained users.

\section{Results}

The characteristics of the study participants are summarised in Table 3.

\subsection{Use errors}

The most common use errors and close calls among patients and caregivers during the first session were use errors commonly related to injection device utilisation: squeeze injection site to create raised area $(n=49 ; 36.0 \%)$, check medication in viewing window $(\mathrm{n}=31 ; 22.8 \%)$, and check expiration date $(\mathrm{n}=31 ; 22.8 \%)$. The numbers of use errors and close calls for these tasks were reduced during the second injection task to $17.6 \%$, $14.7 \%$, and $18.4 \%$, respectively (Figure 3 ). During the second injection, 57 users $(41.9 \%)$ did not rotate the injection site. However, when questioned later, participants knew to avoid an injured area. 
Table 3 Participant demographics

\begin{tabular}{|c|c|c|c|}
\hline Characteristics & $\begin{array}{l}\text { Patients } \\
(n=60)\end{array}$ & $\begin{array}{l}\text { Caregivers } \\
(n=61)\end{array}$ & $\begin{array}{l}\text { Healthcare providers } \\
\quad(n=15)\end{array}$ \\
\hline Age (years), mean (range) & $54.4(25-73)$ & $47.1(20-77)$ & $49.6(26-68)$ \\
\hline Female, $n(\%)$ & $41(68)$ & $37(61)$ & $11(73)$ \\
\hline \multicolumn{4}{|l|}{ Race, $n(\%)$} \\
\hline Black or African American & $6(10)$ & $8(13)$ & $2(13)$ \\
\hline White & $50(83)$ & $50(82)$ & $11(73)$ \\
\hline Other & $4(7)$ & $3(5)$ & $2(13)$ \\
\hline \multicolumn{4}{|l|}{ Education, $n(\%)$} \\
\hline Some high school & $1(2)$ & 0 & 0 \\
\hline High school & $30(50)$ & $39(41)$ & 0 \\
\hline College & $22(36)$ & $25(41)$ & $10(67)$ \\
\hline Postgraduate & $7(12)$ & $11(18)$ & $5(33)$ \\
\hline \multicolumn{4}{|l|}{ Visual acuity, $n(\%)$} \\
\hline $\begin{array}{l}\text { Perfect vision (corrected or } \\
\text { uncorrected) }\end{array}$ & $57(95)$ & $60(98)$ & $15(100)$ \\
\hline $\begin{array}{l}\text { Imperfect vision (corrected or } \\
\text { uncorrected) }\end{array}$ & $3(5)$ & $1(2)$ & 0 \\
\hline \multicolumn{4}{|l|}{ Hearing loss, $n(\%)$} \\
\hline None & $51(85)$ & $57(94)$ & $15(100)$ \\
\hline Mild & $6(10)$ & $2(3)$ & 0 \\
\hline Moderate & $3(5)$ & $2(3)$ & 0 \\
\hline Severe & 0 & 0 & 0 \\
\hline \multicolumn{4}{|c|}{ Hand impairment from RA pain on day of usability session, $n(\%)$} \\
\hline None & 0 & & \\
\hline Mild & $15(50)$ & & \\
\hline Moderate & $14(47)$ & & \\
\hline Severe & $1(3)$ & & \\
\hline $\begin{array}{l}\text { Days/week caring for someone with } \\
R A, \text { mean (range) }\end{array}$ & & $4.5(1-7)$ & \\
\hline $\begin{array}{l}\text { Years of experience treating patients } \\
\text { with } R A \text {, mean (range) }\end{array}$ & & & $10.5(1-20)$ \\
\hline
\end{tabular}

Note: RA indicates rheumatoid arthritis.

During the first simulated injection session, 90.4\% of participants administered a full dose; this proportion increased to $97.8 \%$ during the second simulated injection session. However, five participants (3.7\%) erroneously administered two auto-injections during the initial injection. The risk profile of the biologic assessed the potential harm from this error as moderate. In addition, four use errors occurred because the device was temporarily left uncapped prior to injection. 
When the rates of use errors were compared across groups, caregivers and patients had similar rates of use errors and close calls during the first and second injections. Each group had an overall higher rate of errors in the first session than in the second session. During the first injections, the rate of errors for untrained patients and caregivers was higher than the rate of errors for trained users; however, these rates were similar during the second injections. As expected, rates of errors were higher for caregivers and patients than for healthcare providers.

Figure 3 Instances of use errors and close calls during the first and second injection sessions for all end users $(n=136)$

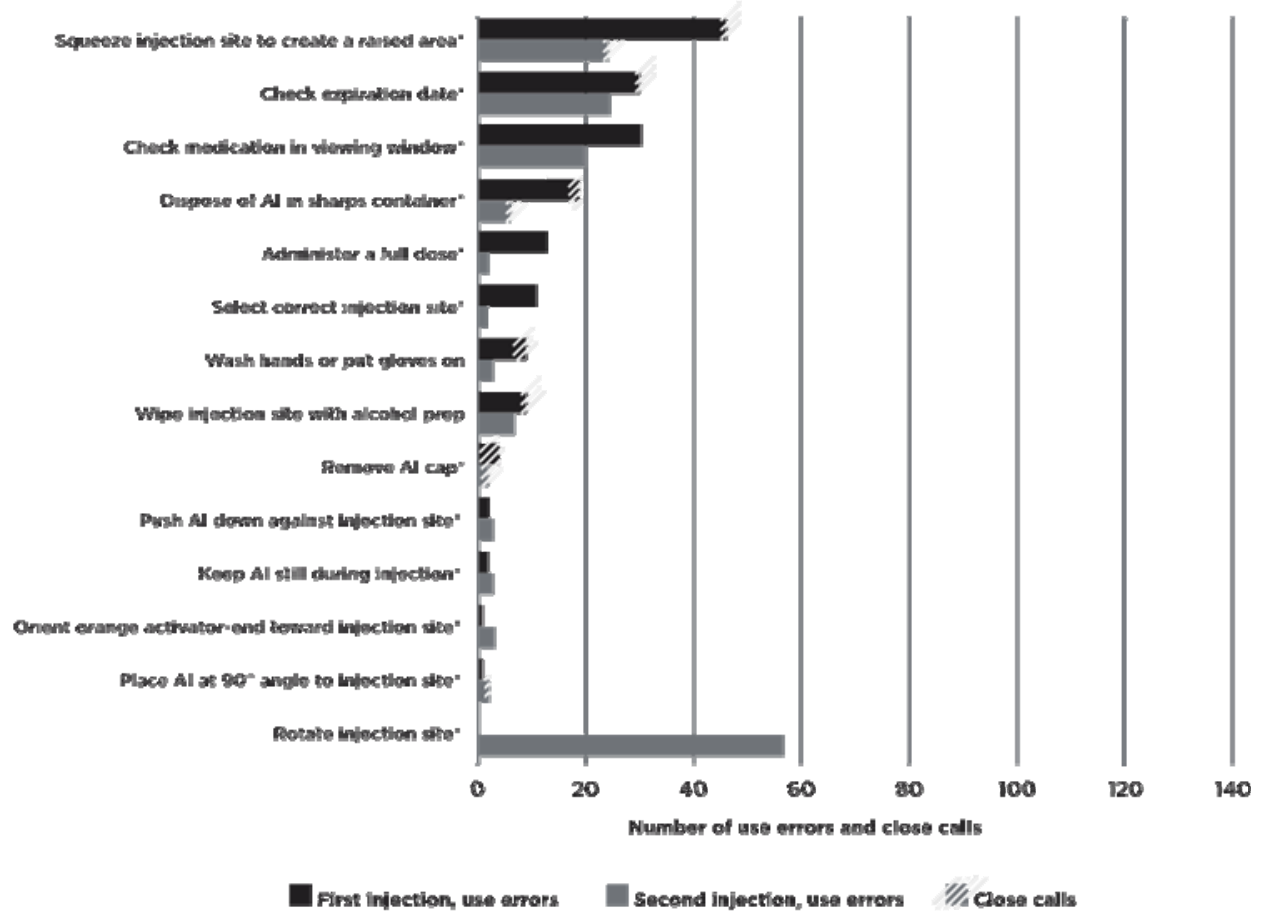

Notes: *Critical task.

$\mathrm{AI}$ indicates auto-injector.

\subsection{Severity of use errors}

The severity of potential harm from use errors ranges from a score of 2 to 10 (Table 4). The most frequent use errors recorded in this study were associated with various levels of severity. Failure to squeeze injection site is associated with a low level of severity (rating of 3), whereas failure to check expiration date or check medication in viewing window are associated with high severity (rating of 7). No use errors documented in this study were considered life-threatening.

Errors that led to potential underdosing or overdosing (e.g., failure to administer full dose, administration of 2 AIs) were relatively uncommon. These errors are of moderate severity and are unlikely to cause serious or life-threatening harm to the patient. 
Table 4 Severity scale of potential harm according to the auto-injector AFMEA

\begin{tabular}{|c|c|c|c|}
\hline Rating & $\begin{array}{l}\text { Severity of } \\
\text { failure }\end{array}$ & Harm to patient & Examples of use steps \\
\hline 10 & Very high & $\begin{array}{l}\text { Death or serious deterioration of } \\
\text { the state of health (e.g., shock, } \\
\text { sepsis, loss of consciousness) }\end{array}$ & - Proper device storage \\
\hline 7 & High & $\begin{array}{l}\text { Persistent or strong discomfort } \\
\text { (e.g., pain, allergic reaction, } \\
\text { infection) }\end{array}$ & $\begin{array}{l}\text { - Check expiration date } \\
\text { - Check medication in viewing window } \\
\text { - Select correct injection site } \\
\text { - Orient orange activator end toward } \\
\text { the injection site } \\
\text { - Keep AI still during injection } \\
\text { - Administer full dose } \\
\text { - Dispose in sharps container }\end{array}$ \\
\hline 5 & Moderate & $\begin{array}{l}\text { Injury or impairment not } \\
\text { requiring professional medical } \\
\text { intervention (e.g., needle-stick } \\
\text { injury with sterile needle) }\end{array}$ & $\begin{array}{l}\text { - Wipe injection site with an alcohol } \\
\text { prep } \\
\text { - Remove device cap } \\
\text { - Push the body of the AI down against } \\
\text { the injection site } \\
\text { - Hold AI to injection site until viewing } \\
\text { window is blocked by orange and } \\
\text { count to } 10\end{array}$ \\
\hline 3 & Low & $\begin{array}{l}\text { Inconvenience of temporary } \\
\text { minor discomfort (e.g., local } \\
\text { reddening of the skin) }\end{array}$ & $\begin{array}{l}\text { - Squeeze injection site to create a } \\
\text { raised area } \\
\text { - Pull AI straight away from injection } \\
\text { site }\end{array}$ \\
\hline 2 & Very low & None & \\
\hline
\end{tabular}

Note: AFMEA indicates advanced Failure Modes and Effects Analysis; AI, auto-injector.

\subsection{Product knowledge}

Product knowledge was evaluated through a verbal knowledge assessment, including questions about the critical task of proper device storage. As shown in Figure 4, most users responded correctly to queries about various aspects of AI use. A total of $90 \%$ of users indicated that they would not administer a second dose when troubleshooting an incomplete dose. After consulting the instructions for use (IFU), the remaining $10 \%$ of participants correctly answered that they would not take the second dose. Similarly, 90\% of users indicated that they would complete the injection after an unexpected interruption, and, after consulting the IFU, $8 \%$ correctly answered that they would complete the injection. The remaining $2 \%$ could not find anything in the instructions about this topic. The IFU also clarified proper storage for participants who incorrectly stated that they would not store in a refrigerator or would store within reach of children. 
Figure 4 Product knowledge assessment

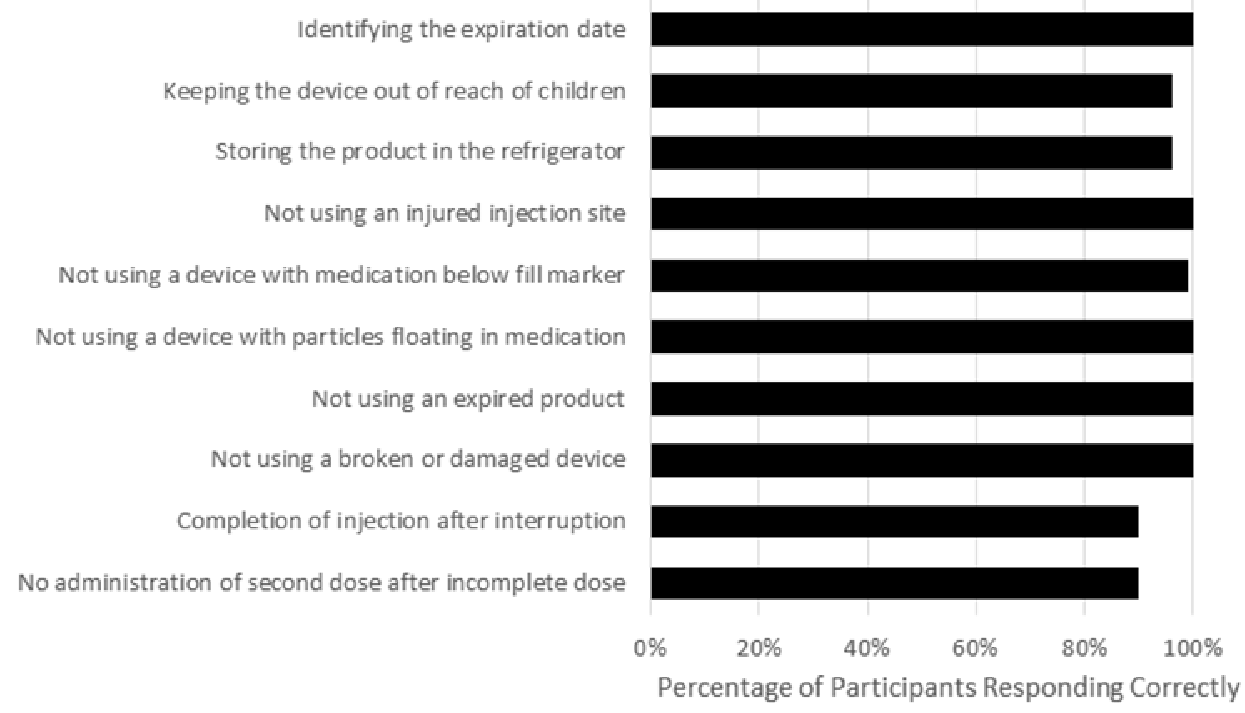

\subsection{Subjective feedback}

Participants were asked to rate the ease of use of the product and its accompanying instructional materials, as well as the clarity of specific topics described in the instructional materials. The responses to these questions are summarised in Figure 5. Overall, most participants stated that the IFU were very easy to use and very clear. The IFU included instructions on correct administration areas of the AI, which is important because the choice of injection site may impact successful completion of a subcutaneous injection.

\subsection{Adverse events}

Two adverse events (AEs) occurred during the study. One patient pushed down on the orange activator and poked herself with the needle; however, she did not press down hard enough to activate the AI. She did not report a puncture, nor did she see blood. The AE resolved within three days. The second AE occurred when a patient oriented the AI upside down and activated it into the skin. The needle touched the skin; there was neither puncture nor blood. The AE was considered resolved immediately.

FKB addressed the risk for needle puncture due to improper orientation of the AI by applying additional on-device labeling to indicate the needle end of the AI and proper orientation to the injection site. These new risk-control measures were evaluated in a subsequent focused human factors validation study with 60 representative end users. No errors of improper orientation of the AI occurred.

Two serious AEs occurred during the study. Both were unrelated to the study activities and device and did not affect patient participation in the study. 
Figure 5 Clarity of materials provided (IFU/QRG) (see online version for colours)

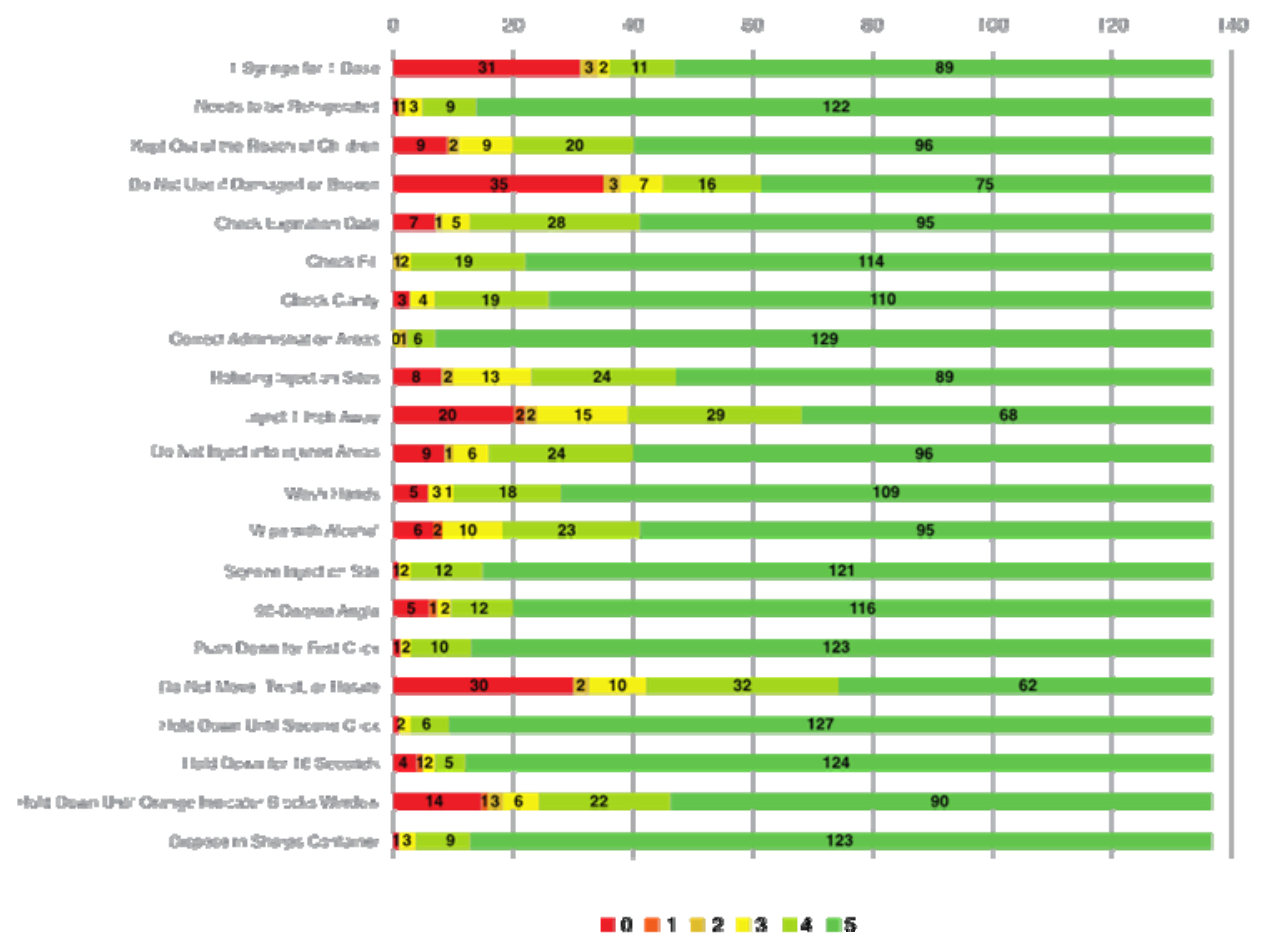

Notes: Subjective feedback was provided by all participants on a modified Likert scale from 1 (very unclear) to 5 (very clear). A score of 0 indicated "did not see in the materials provided."

IFU indicates instructions for use; QRG, quick reference guide.

\section{Discussion}

Medical errors are relatively common occurrences in the USA, with up to 98,000 deaths each year attributable to preventable medical errors (IOM Committee on Quality of Health Care in America, 2000). In addition to the cost to human lives, medical errors also are burdensome in terms of economic costs, morbidity, decreased treatment effectiveness, and decreased patient satisfaction. Errors are often caused by faulty conditions that lead to mistakes, underscoring the importance of careful product design to decrease or eliminate use errors. Furthermore, systems interventions, such as training on device utilisation, are key to improving usability (US Food and Drug Administration, 2016; IOM Committee on Quality of Health Care in America, 2000; Wittich et al., 2014).

In this usability validation study, the FKB327-AI device was shown to be used safely and correctly, with high rates of success by representative end users. Furthermore, the tobe-marketed materials were clear and easily understood. More than $90 \%$ of injections were completed successfully on the first try, and that percentage exceeded $98 \%$ with a subsequent try. Among the errors made by end users, most were of moderate or low severity. High severity errors (e.g., failure to check expiration date, select correct injection site, or dispose in a sharps container) were uncommon and were reduced in 
frequency from the first to second injection. Furthermore, training from a nurse educator was associated with a lower rate of errors during the initial injection session. The rate of errors decreased from the first to the second injection, eliminating the disparities between trained and untrained individuals, and suggesting that, with practice, the FKB327-AI device is associated with a low residual risk for errors.

The patient and caregiver populations in this study had varied age, education, visual acuity, hearing loss, and disease-related symptoms, representative of a heterogeneous population of end users. Importantly, all patients had some level of hand pain when not receiving medication, and on the day of the session, half of all patient participants had moderate or severe levels of pain. The results of this study suggest that hand disability and deformity, as shown in Figure 1, are likely not barriers to proper use of FKB327-AI, an important characteristic for anti-RA drugs. The haptic features of FKB327-AI that improve its usability among patients and caregivers with hand pain include a non-slippery body, an optimal diameter of $18.2 \mathrm{~mm}$, low trigger force without need to press a button, and a non-slippery needle cap for gripping. Future studies could include evaluation of a population enriched for older patients with severe disease, hand disability, and/or frailty to confirm these findings.

Critical tasks for the proper use of FKB327-AI are those that could result in either a high severity of harm or in compromised medical care (e.g., no treatment). Because of the preponderance of critical tasks, most use errors and close calls documented in this study occurred during performance of critical tasks. Failure to successfully complete critical tasks had a range of clinical implications, from microbiological contamination to administration of ineffective, degraded, or precipitated product. Although these errors could result in impairment or persistent discomfort, none of the errors identified were life-threatening. Indeed, the only critical task identified as potentially life-threatening in the case of failure was improper storage of the device within reach of children, due to the risk for swallowing parts. The vast majority of participants were able to correctly explain that the device should be stored out of reach of children.

Potential device-specific errors (e.g., failure to remove cap or failure to orient device properly) occurred very infrequently. Most errors that occurred in this study are common to self-injection processes and have been reported in previous usability studies of other AI devices. Of the 13 categories of use errors observed in the present usability study, 12 were previously reported in other studies of AI device usability, according to the results of a systematic review that analysed the results of 38 studies and 232 use errors and close calls. Only failure to rotate injection site was not reported as an error in the systematic review; however, no data about a second injection were discussed, suggesting that this task may not have been evaluated in any of the reviewed publications (Weinhold et al., 2018).

A benefit-risk analysis of FKB327-AI has also been performed, and the low proportion of device-specific use errors and close calls is likely attributable to several user-focused FKB327-AI design features. For example, FKB327-AI has a one-step activation process that eliminates the need for priming and activating the device; users simply have to place the device against the injection site and press down to initiate the injection. Furthermore, the AI requires low trigger force to activate the needle and the body has an easy-to-grip, non-slippery exterior. This feature is likely particularly beneficial for patients with RA who have hand or wrist disability or deformity. The three feedback indicators for full dose delivery are audible clicks, orange indicator in the viewing window, and length of time since the start of the injection. Device labelling was 
added to clearly indicate the needle end, whereas outer and inner packaging were developed to be easy to use. Furthermore, risk mitigation factors were applied to prevent needle puncture (additional labelling), and a subsequent study supports the success of those features, as no incidents of incorrect device orientation or needle punctures occurred in that study. After these and other design and labelling risk mitigations, residual risks have been determined to be non-specific to the FKB327-AI, and additional risk mitigations were not expected to further reduce errors. The results of the present usability validation study support the findings of this benefit-risk analysis and are suggestive of few residual product-specific risks.

\section{Conclusions}

FKB327-AI is an easy-to-use device with clear packaging and instructional materials. The device and its materials were associated with few device-specific errors and no use errors leading to life-threatening or serious harm. Errors that led to administering an incorrect dose were infrequent, not associated with potentially life-threatening or serious harm, and largely corrected after administering the first dose. The results of this study further support the results of a previous benefit-risk analysis, which showed that the design of the FKB327-AI leads to safe and correct use by end users, and the benefits of the FKB327-AI outweigh the residual risks associated with its use.

\section{References}

Bligård, L.O. and Osvalder, A.L. (2014) 'Predictive use error analysis - Development of AEA, SHERPA and PHEA to better predict, identify and present use errors', International Journal of Industrial Ergonomics, Vol. 44, No. 1, pp.153-170.

Bluett, J., Morgan, C., Thurston, L., Plant, D., Hyrich, K.L., Morgan, A.W., Wilson, A.G., Isaacs, J.D., Cordingley, L., Barton, A. and BRAGGSS (2015) 'Impact of inadequate adherence on response to subcutaneously administered anti-tumour necrosis factor drugs: results from the biologics in rheumatoid arthritis genetics and genomics study syndicate cohort', Rheumatology (Oxford), Vol. 54, No. 3, pp.494-499.

Dashiell-Aje, E., Harding, G., Pascoe, K., DeVries, J., Berry, P. and Ramachandran, S. (2018) 'Patient evaluation of satisfaction and outcomes with an autoinjector for self-administration of subcutaneous belimumab in patients with systemic lupus erythematosus', Patient, Vol. 11, No. 1, pp.119-129.

Erol, A.M., Ceceli, E., Uysal Ramadan, S. and Borman P. (2016) 'Effect of rheumatoid arthritis on strength, dexterity, coordination and functional status of the hand: the relationship with magnetic resonance imaging findings', Acta Reumatológica Portuguesa, Vol. 41, No. 4, pp.328-337.

Grewal, S., Ramsey, S., Balu, S. and Carlson, J.J. (2018) 'Cost-savings for biosimilars in the United States: a theoretical framework and budget impact case study application using filgrastim', Expert Review of Pharmacoeconomics \& Outcomes Research, Vol. 18, No. 4, pp.447-454.

Hegde, V. and Respironics, P. (2013) 'Role of human factors/usability engineering in medical device design', 2013 Proceedings Annual Reliability and Maintainability Symposium (RAMS), Orlando, FL, pp.1-5. 
Helmick, C.G., Felson, D.T., Lawrence, R.C., Gabriel, S., Hirsch, R., Kwoh, C.K., Liang, M.H., Kremers, H.M., Mayes, M.D., Merkel, P.A., Pillemer, S.R., Reveille, J.D. and Stone, J.H.; National Arthritis Data Workgroup. (2008) 'Estimates of the prevalence of arthritis and other rheumatic conditions in the United States. Part I', Arthritis \& Rheumatology, Vol. 58, No. 1, pp.15-25.

Hooper, D.A. and Hitchens, R.E. (2011) 'Use error analysis in a medical device product development cycle', Proceedings of the Human Factors and Ergonomics Society Annual Meeting, Vol. 55, No. 1, pp.1803-1807.

Hunter, T.M., Boytsov, N.N., Zhang, X., Schroeder, K., Michaud, K. and Araujo, A.B. (2017) 'Prevalence of rheumatoid arthritis in the United States adult population in healthcare claims databases, 2004-2014', Rheumatology International, Vol. 37, No. 9, pp.1551-1557.

Institute of Medicine Committee on Health Literacy (2004) Health Literacy: A Prescription to End Confusion, National Academies Press, Washington, DC.

Institute of Medicine Committee on Quality of Health Care in America (2000) To Err is Human: Building a Safer Health System, National Academies Press (US), Washington, DC.

Kivitz, A., Cohen, S., Dowd, J.E., Edwards, W., Thakker, S., Wellborne, F.R., Renz, C.L. and Segurado, O.G. (2006) 'Clinical assessment of pain, tolerability, and preference of an autoinjection pen versus a prefilled syringe for patient self-administration of the fully human, monoclonal antibody adalimumab: the TOUCH trial', Clinical Therapeutics, Vol. 28, No. 10, pp.1619-1629.

Medicines \& Healthcare products Regulatory Agency (2017) Human Factors and Usability Engineering - Guidance for Medical Devices Including Drug-device Combination Products, September [online] https://assets.publishing.service.gov.uk/government/uploads/system/ uploads/attachment_data/file/645862/HumanFactors_Medical-Devices_v1.0.pdf (accessed 12 February 2020).

Murage, M.J., Tongbram, V., Feldman, S.R., Malatestinic, W.N., Larmore, C.J., Muram, T.M., Burge, R.T., Bay, C., Johnson, N., Clifford S. and Araujo, A.B. (2018) 'Medication adherence and persistence in patients with rheumatoid arthritis, psoriasis, and psoriatic arthritis: a systematic literature review', Patient Preference \& Adherence, Vol. 12, pp.1483-1503.

Ostrowska, M., Maśliński, W., Prochorec-Sobieszek, M., Nieciecki, M. and Sudol-Szopinska, I. (2018) 'Cartilage and bone damage in rheumatoid arthritis', Reumatologia, Vol. 56, No. 2, pp.111-120.

Paul, C., Stalder, J.F., Thaçi, D., Vincendon, P., Brault, Y., Kielar, D. and Tebbs, V. (2012) 'Patient satisfaction with injection devices: a randomized controlled study comparing two different etanercept delivery systems in moderate to severe psoriasis', Journal of the European Academy of Dermatology and Venereology, Vol. 26, No. 4, pp. 448-455.

Schulze-Koops, H., Giacomelli, R., Samborski, W., Rednic, S., Herold, M., Yao, R., Govoni, M., Vastesaeger, N. and Weng, H.H. (2015) 'Factors influencing the patient evaluation of injection experience with the SmartJect autoinjector in rheumatoid arthritis', Clinical and Experimental Rheumatology, Vol. 33, No. 2, pp. 201-208.

Schwarzenbach, F., Dao Trong, M., Grange, L., Laurent, P.E., Abry, H., Cotton, J. and Granger, C. (2014) 'Results of a human factors experiment of the usability and patient acceptance of a new autoinjector in patients with rheumatoid arthritis', Patient Preference \& Adherence, Vol. 8, pp.199-209.

Singh, J.A., Saag, K.G., Bridges, S.L., Jr., Akl, E.A., Bannuru, R.R., Sullivan, M.C., Vaysbrot, E., McNaughton, C., Osani, M., Shmerling, R.H., Curtis, J.R., Furst, D.E., Parks, D., Kavanaugh, A., O’Dell, J., King, C., Leong, A., Matteson, E.L., Schousboe, J.T., Drevlow, B., Ginsberg, S., Grober, J., St Clair, E.W., Tindall, E., Miller, A.S. and McAlindon, T. (2016) '2015 American College of Rheumatology Guideline for the Treatment of Rheumatoid Arthritis', Arthritis Care \& Research (Hoboken), Vol. 68, No. 1, pp.1-25.

Smolen, J.S., Aletaha, D. and McInnes, I.B. (2016) 'Rheumatoid arthritis', The Lancet, Vol. 388, No. 10055, pp.2023-2038. 
Stockl, K., Ory, C., Vanderplas, A., Nicklasson, L., Lyness, W., Cobden, D. and Chang, E. (2007) 'An evaluation of patient preference for an alternative insulin delivery system compared to standard vial and syringe', Current Medical Research and Opinion, Vol. 23, No. 1, pp.133-146.

US Food and Drug Administration (2016) Applying Human Factors and Usability Engineering to Medical Devices, 3 February [online] http://www.fda.gov/downloads/medicaldevices/.../ ucm259760.pdf (accessed 8 December 2019).

US Food and Drug Administration (2016) Human Factors Studies and Related Clinical Study Considerations in Combination Product Design and Development, February [online] http://www.fda.gov/downloads/regulatoryinformation/guidances/ucm484345.pdf (accessed 8 December 2019).

Weinhold, T., Del Zotto, M., Rochat, J., Schiro, J., Pelayo, S. and Marcilly, R. (2018) 'Improving the safety of disposable auto-injection devices: a systematic review of use errors', AAPS Open, Vol. 4, No. 7.

Wittich, C.M., Burkle, C.M. and Lanier, W.L. (2014) 'Medication errors: an overview for clinicians', Mayo Clinic Proceedings, Vol. 89, No. 8, pp.1116-1125.

Xiao, X., Li, W., Clawson, C., Karvani, D., Sondag, P. and Hahn, J.K. (2018) 'Evaluation of performance, acceptance, and compliance of an auto-injector in healthy and rheumatoid arthritic subjects measured by a motion capture system', Patient Preference \& Adherence, Vol. 12, pp.515-526. 